\title{
EFICIÊNCIA NUTRICIONAL E APROVEITAMENTO DO NITROGÊNIO PELO CAPIM-MARANDU DE PASTAGEM EM ESTÁGIO MODERADO DE DEGRADAÇÃO SOB DOSES E FONTES DE NITROGÊNIO ${ }^{1}$
}

\author{
Nutritional efficiency and nitrogen uptake by capim-marandu at pasture in moderate \\ stage of degradation under doses and sources of nitrogen ${ }^{1}$ \\ Douglas Ramos Guelfi Silva', Kátia Aparecida de Pinho Costa ${ }^{3}$, Valdemar Faquin 4 , \\ Itamar Pereira de Oliveira ${ }^{5}$, Milena Rízzia Ferreira de Souza ${ }^{6}$, Marcos André Silva Souza ${ }^{7}$
}

\begin{abstract}
RESUMO
O presente estudo foi desenvolvido sob condições de campo, visando avaliar a eficiência no uso e no aproveitamento do nitrogênio pelo capim-marandu por meio de diversos índices. $\mathrm{O}$ experimento foi conduzido na Fazenda Modelo da Universidade Estadual de Goiás (UEG) num Latossolo Vermelho distrófico, no período de julho de 2003 a março de 2006. O delineamento experimental utilizado foi de blocos ao acaso, com três repetições. Os tratamentos nas parcelas foram caracterizados por um fatorial $2 \times 4$, sendo duas fontes de $\mathrm{N}$ (sulfato de amônio e uréia) e quatro doses de $\mathrm{N}(0,100,200$ e $300 \mathrm{~kg} / \mathrm{ha}$ ). Na subparcela, os tratamentos foram representados pelos anos $(2004,2005$ e 2006), referentes ao tempo de recuperação da pastagem. A adubação nitrogenada foi parcelada em três aplicações após cada corte de avaliação da forrageira. Foram realizados três cortes da forrageira por ano, avaliando-se a massa seca e os teores de N nos tecidos. Com esses resultados, avaliaram-se os índices de Eficiência de Utilização do N (EUN), Recuperação do N Aplicado (RNA), Eficiência Agronômica do N Aplicado (EA) e Eficiência Fisiológica (EF) ou Eficiência Biológica. Os resultados mostraram que a EUN aumentou, enquanto que a RNA, EA e a EF diminuíram com o aumento das doses de $\mathrm{N}$ aplicadas. Em todos os casos, os índices foram influenciados pelos anos de recuperação da forrageira estudados, mas não pelas fontes de $\mathrm{N}$.
\end{abstract}

Termos para indexação: Adubação nitrogenada, sulfato de amônio, eficiência no uso do nitrogênio, uréia.

\begin{abstract}
This study was accomplished under field conditions, to evaluate the use and efficiency of nitrogen uptake, through various indexes, in pasture of Brachiaria brizantha. The experiment was conduced at the Model Farm of the Goiás State University in a distrophic Dark Red Latosol, from 2003 July to 2006 March. The experimental design was randon blocks, with three replicates. The treatments were placed in parcels characterized by a $2 \mathrm{x} 4$ factorial, with two sources of $\mathrm{N}$ (ammonium sulfate and urea) and four doses of $\mathrm{N}(0,100,200$ and $300 \mathrm{~kg} / \mathrm{ha} /$ year $)$. In sub - parcel, the treatments were represented per years $(2004,2005$ and 2006$)$ refering to time of pasture recovery. The use of nitrogen was divided in three times, after each cut evaluation of the forage pasture. Three cuts were made per year, evaluating dry mass and $\mathrm{N}$ accumulation in the tissue. Nitrogen Utilization Efficiency, Recovery from the $\mathrm{N}$ Applied, Agronomic Efficiency from the N Applied, Physiological or Biological Efficiency indexes were evaluated. The results showed that EUN increased, while RNA, EA and EF reduced with the increase in the $\mathrm{N}$ doses applied. In all cases, the indexes were influenced by the years of recovery the herbage, and not by the sources of $\mathrm{N}$.
\end{abstract}

Index terms: Nitrogen fertilization, ammonium sulfate, nitrogen use efficiency, urea.

(Recebido em 10 de outubro de 2008 e aprovado em 13 de julho de 2010)

\section{INTRODUÇÃO}

Os fertilizantes nitrogenados, quando manejados de forma inadequada apresentam-se como potenciais poluidores do meio ambiente, porque podem ser perdidos quando aplicados no solo por lixiviação ou desnitrificação, reduzindo a eficiência da adubação.

A eficiência de uso ou a percentagem de recuperação pelas plantas do $\mathrm{N}$ (nitrogênio) proveniente dos fertilizantes nitrogenados é estimada com a utilização de adubos marcados com o isótopo ${ }^{15} \mathrm{~N}$ ou pelos métodos que medem a diferença entre a quantidade de $\mathrm{N}$ absorvida por plantas não adubadas em comparação com aquelas que receberam N (Fageria, 1998; Cantarella, 2007).

A eficiência de utilização do $\mathrm{N}$ para a produção de alimentos no mundo é muito baixa. A recuperação do $\mathrm{N}$ dos fertilizantes nitrogenados pode variar com a espécie

\footnotetext{
${ }^{1}$ Parte da dissertação de Mestrado em Ciência do Solo, apresentada pelo primeiro autor à Universidade Federal de Lavras/UFLA - Lavras, MG 2Universidade Federal de Lavras/UFLA - Departamento de Ciência do Solo/DCS - Cx. P. 3037 - 37200-000 - Lavras, MG - douglasguelfi@dcs.ufla.br ${ }^{3}$ Instituto Federal de Educação, Ciência e Tecnologia Goiano - Iporá, GO

${ }^{4}$ Universidade Federal de Lavras/UFLA - Departamento de Ciência do Solo/DCS - Lavras, MG

${ }^{5}$ Faculdade Montes Belos/FMB - São Luis de Montes Belos, GO

${ }^{6}$ Universidade Estadual de Goiás/UEG - São Luis de Montes Belos, GO

${ }^{7}$ Universidade de Rio Verde - Rio Verde, GO
} 
vegetal, práticas de manejo, propriedades do solo, condições ambientais e fonte de $\mathrm{N}$ utilizada (Shaviv, 2001; Pegoraro et al., 2009; Espindula, 2010).

Dessa forma, a maximização da eficiência de conversão do N no fertilizante em massa seca de forragem é extremamente importante para o resultado bioeconômico final da adubação nitrogenada em pastagens (Martha Júnior et al., 2007).

Diante disso, objetivou-se, com o presente trabalho avaliar diversos índices de eficiência de utilização e de aproveitamento do $\mathrm{N}$ no capim-marandu de pastagem em estágio moderado de degradação, sob doses e fontes de $\mathrm{N}$, por um período de três anos.

\section{MATERIAL E MÉTODOS}

O experimento foi conduzido, de julho de 2003 a março de 2006, na Fazenda Modelo do Curso de Zootecnia da Universidade Estadual de Goiás, em São Luís de Montes Belos-GO, a $579 \mathrm{~m}$ de altitude, 16 $31^{\circ} 30^{\prime}$ de latitude sul e $50^{\circ} 22^{\prime} 20^{\prime \prime}$ de longitude oeste. A área utilizada de pastagem foi de $882 \mathrm{~m}^{2}$, dividida em três blocos de $294 \mathrm{~m}^{2}$, com parcelas individuais de $20 \mathrm{~m}^{2}$ e área útil de $6 \mathrm{~m}^{2}$.

O delineamento experimental utilizado foi de blocos ao acaso, com três repetições. Os tratamentos nas parcelas foram caracterizados por um fatorial $2 \times 4$, sendo duas fontes de $\mathrm{N}$ (sulfato de amônio e uréia) e quatro doses de $\mathrm{N}(0,100,200$ e $300 \mathrm{~kg} / \mathrm{ha})$. Na subparcela, os tratamentos foram representados pelos anos (2004, 2005 e 2006), referentes ao tempo de recuperação da pastagem.

O solo foi classificado originalmente como Latossolo Vermelho eutrófico (Empresa, 2006), de textura argilosa, cujas médias das características químicas de todos os anos, na profundidade de $0-20 \mathrm{~cm}$, estão apresentadas na Tabela 1. A metodologia utilizada para a análise de solo foi a da Embrapa (1997).

O fertigrama com a evolução da interpretação dos resultados das características químicas e disponibilidade de nutrientes no solo da pastagem em recuperação é apresentado na Figura 1.

No primeiro ano (2003), foram aplicados $500 \mathrm{~kg} / \mathrm{ha}$ de calcário dolomítico com $85 \%$ de PRNT, em cobertura 60 dias, antes do período chuvoso. Em setembro, após as primeiras chuvas foram aplicados $150 \mathrm{~kg} / \mathrm{ha}$ de $\mathrm{P}_{2} \mathrm{O}_{5}, 18 \mathrm{~kg} / \mathrm{ha}$ de $\mathrm{S}, 80$ $\mathrm{kg} / \mathrm{ha}$ de $\mathrm{K}_{2} \mathrm{O}$ e $30 \mathrm{~kg} / \mathrm{ha}$ de FTE BR-12, utilizando-se como fontes: super fosfato simples, cloreto de potássio e fritas, respectivamente. A partir dos resultados da análise em amostra de solo do segundo ano (2004), foi realizada adubação de manutenção com $50 \mathrm{~kg} / \mathrm{ha}$ de $\mathrm{P}_{2} \mathrm{O}_{5}, 6 \mathrm{~kg} / \mathrm{ha}$ de $\mathrm{S}$ e $100 \mathrm{~kg} / \mathrm{ha}$ de $\mathrm{K}_{2} \mathrm{O}$, provenientes das fontes de super fosfato simples e cloreto de potássio, respectivamente. No terceiro ano de recuperação (2005), foram aplicados $150 \mathrm{~kg} / \mathrm{ha}$ de $\mathrm{P}_{2} \mathrm{O}_{5}, 18 \mathrm{~kg} /$ ha de $\mathrm{S}, 120 \mathrm{~kg} / \mathrm{ha}$ de $\mathrm{K}_{2} \mathrm{O}$ e $20 \mathrm{~kg} / \mathrm{ha}$ de FTEBR-12, na forma de super fosfato simples, cloreto de potássio e fritas, respectivamente. A adubação de manutenção foi realizada de acordo com Sousa \& Lobato (2004), sendo toda adubação realizada com uma única aplicação a lanço no início do período chuvoso (setembro), antes dos fertilizantes nitrogenados.

Tabela 1 - Características químicas do solo, realizadas antes da adubação de manutenção e dos tratamentos, nos anos de condução do experimento.

\begin{tabular}{|c|c|c|c|}
\hline Características & 2003 & 2004 & 2005 \\
\hline $\mathrm{pH}\left(\mathrm{CaCl}_{2}\right)$ & 5,2 & 5,1 & 4,6 \\
\hline $\mathrm{Al}\left(\mathrm{cmol}_{\mathrm{c}} \mathrm{dm}^{-3}\right)$ & 0,0 & 0,1 & 0,2 \\
\hline $\mathrm{H}+\mathrm{Al}\left(\mathrm{cmol}_{\mathrm{c}} \mathrm{dm}^{-3}\right)$ & 3,9 & 5,3 & 3,5 \\
\hline $\mathrm{Ca}\left(\mathrm{cmol}_{\mathrm{c}} \mathrm{dm}^{-3}\right)$ & 2,70 & 2,79 & 2,20 \\
\hline $\mathrm{Mg}\left(\mathrm{cmol}_{\mathrm{c}} \mathrm{dm}^{-3}\right)$ & 1,00 & 0,91 & 0,23 \\
\hline $\mathrm{K}\left(\mathrm{cmol}_{\mathrm{c}} \mathrm{dm}^{-3}\right)$ & 0,42 & 0,23 & 0,11 \\
\hline P- Mehlich $1\left(\mathrm{mg} \mathrm{dm}^{-3}\right)$ & 1,3 & 6,4 & 1,8 \\
\hline $\mathrm{SO}_{4}^{-2}\left(\mathrm{cmol}_{\mathrm{c}} \mathrm{dm}^{-3}\right)$ & 9,8 & 18,9 & 30,0 \\
\hline $\mathrm{Cu}\left(\mathrm{mg} \mathrm{dm}^{-3}\right)$ & 0,4 & 1,7 & 1,0 \\
\hline $\mathrm{Zn}\left(\mathrm{mg} \mathrm{dm}^{-3}\right)$ & 0,2 & 2,9 & 0,7 \\
\hline $\mathrm{Fe}\left(\mathrm{mg} \mathrm{dm}^{-3}\right)$ & 13,0 & 30,0 & 31,3 \\
\hline $\operatorname{Mn}\left(\mathrm{mg} \mathrm{dm}^{-3}\right)$ & 27,4 & 41,0 & 15,6 \\
\hline $\operatorname{MOS}\left(\mathrm{g} \mathrm{dm}^{-3}\right)$ & 11,0 & 18,0 & 20,0 \\
\hline CTC pH 7,0 $\left(\mathrm{cmol}_{\mathrm{c}} \mathrm{dm}^{-3}\right)$ & 8,0 & 8,2 & 6,5 \\
\hline
\end{tabular}

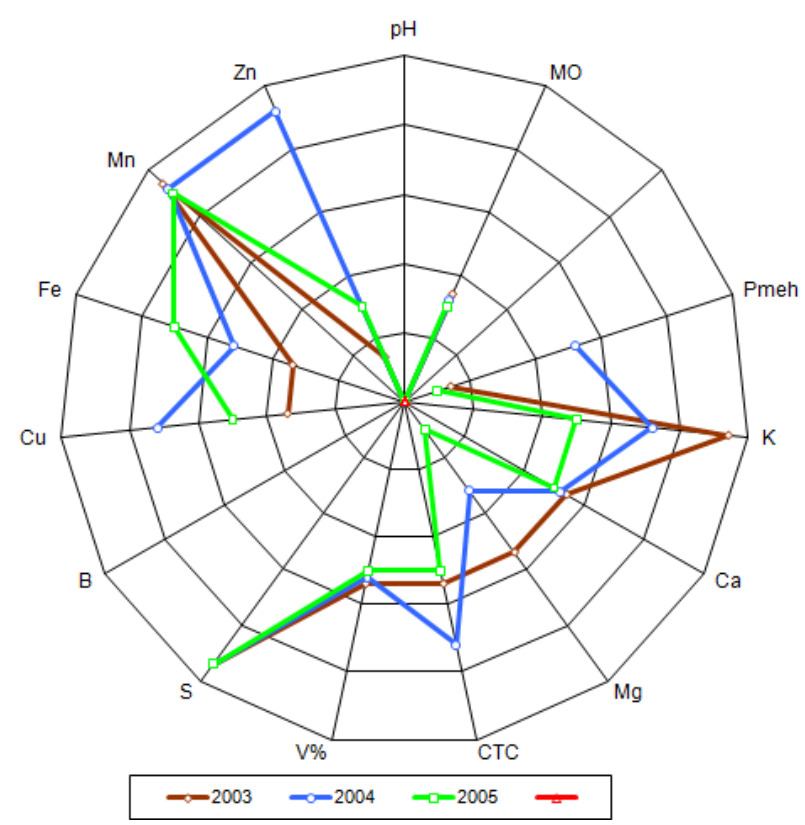

Figura 1 - Fertigrama com a interpretação das classes de fertilidade do solo e disponibilidade de macronutrientes e micronutrientes. 
A adubação nitrogenada, em cada ano, foi parcelada em três épocas, imediatamente após cada corte da forrageira, sendo que a primeira aplicação foi realizada em dezembro, a segunda em janeiro e a terceira em fevereiro, todas com intervalo de trinta dias.

Foram realizados três cortes da planta forrageira por ano. O primeiro trinta dias após a aplicação dos fertilizantes nitrogenados (janeiro), o segundo trinta dias após o primeiro (fevereiro) e o terceiro trinta dias após o segundo (março).

A planta forrageira foi coletada com auxílio de um quadrado de ferro de $1 \times 1 \mathrm{~m}$ e cortada com tesoura de aço na altura de $20 \mathrm{~cm}$ da superfície do solo. Após cada corte de avaliação, foi realizado o corte de uniformização de toda a área experimental na mesma altura de corte das plantas avaliadas, sendo retirado da área o resíduo dessa uniformização.

O material coletado no campo foi acondicionado em sacos plásticos e enviado ao laboratório, onde foi retirada uma amostra representativa de cada parcela, de aproximadamente $500 \mathrm{~g}$. Posteriormente, o material foi colocado em estufa de ventilação forçada de ar, com temperatura entre 58 e $65^{\circ} \mathrm{C}$ por $72 \mathrm{~h}$, para secagem. Posteriormente, as amostras foram moídas em moinho do tipo Wiley, passadas em peneira de $1 \mathrm{~mm}$ e armazenadas em sacos plásticos.

Foi realizada a análise química de nitrogênio da planta para se obter o teor de nitrogênio total de acordo com metodologia descrita por Malavolta et al. (1997).

Os valores de acúmulo de $\mathrm{N}$ foram obtidos pelo teor de $\mathrm{N}$ na planta e a produção de massa seca (MS). Com os dados de massa seca e acúmulo de $\mathrm{N}$, foram calculados os seguintes índices:

- Eficiência de Utilização de Nitrogênio $($ EUN $)=$ (Massa Seca total, $\mathrm{kg})^{2} /$ (acúmulo de N, g); em (kg de MS) $/ \mathrm{g}$ de N acumulado (Siddiqi \& Glass, 1981);

- Recuperação do Nitrogênio Aplicado (RNA) = Acúmulo de $\mathrm{N}(\mathrm{kg})$ com adubação - Acúmulo de $\mathrm{N}(\mathrm{kg})$ sem adubação / Dose de N aplicada (kg) x 100; em \% (Fageria, 1998).

- Eficiência Agronômica do N Aplicado (EA) = Massa seca com adubação (kg) - Massa Seca sem adubação (kg) / Dose de N (kg); em kg de MS / kg N aplicado (Fageria, 1998).

- Eficiência Fisiológica (EF) ou Eficiência Biológica $=$ Massa Seca com adubação $(\mathrm{kg})-$ Massa Seca sem adubação (kg) / Acúmulo de $\mathrm{N}$ com adubação (kg) Acúmulo de N sem adubação (kg); em kg de MS / kg de N acumulado (Fageria, 1998).
Todas as variáveis receberam o tratamento estatístico pelo software SISVAR 4.6 (Ferreira, 2000). Foi realizada a análise de variância e, em função da significância para as variáveis, foram ajustadas equações de regressão. Utilizou-se o nível de significância de $5 \%$ em todos os testes estatísticos.

\section{RESULTADOS E DISCUSSÃO}

A EUN não foi influenciada pelas doses e fontes de N. Entretanto, foi observado efeito significativo $(\mathrm{P}<0,05) \mathrm{de}$ doses e anos de recuperação da pastagem. Observa-se na Figura 2A, ajustes quadráticos para todos os anos avaliados. A EUN aumentou com o acréscimo das doses de $\mathrm{N}$ aplicadas e seus valores variaram de 0,2119 (no ano de 2005 sem aplicação de $\mathrm{N}$ ) até $0,5260 \mathrm{~kg}^{2} / \mathrm{g}$ (no ano de 2004 na dose máxima), mostrando diferença de $61 \%$ quando comparados. As maiores EUN foram observadas nas doses de 345, 272 e $203 \mathrm{~kg} / \mathrm{ha} /$ ano para os anos de 2004, 2005 e 2006, mostrando um aumento de 144, 126 e 51,8\% em relação à não aplicação do nitrogênio, respectivamente.

Siddiqi \& Glass (1981) relataram que o crescimento da planta está, também, relacionado à concentração do nutriente nos tecidos e não somente na quantidade absoluta acumulada, pois o crescimento só ocorre a partir de uma concentração mínima no tecido vegetal, que é diferente entre espécies ou variedades.

Nesse sentido, Silva (2007) mostra respostas crescentes da altura, densidade de perfílhos, índice de área foliar, matéria seca de lâminas foliares e de colmos mais bainhas da forrageira, respectivamente, às doses de $\mathrm{N}$ aplicadas, buscando, certamente, essa mínima concentração de $\mathrm{N}$ no solo e nos tecidos para expressar a máxima eficiência de utilização.

A recuperação do $\mathrm{N}$ aplicado (RNA) pelo fertilizante refere-se à percentagem do total de $\mathrm{N}$ aplicado pelas fontes que foi absorvida e acumulada adicionalmente pelas plantas das parcelas adubadas em relação às não adubadas (Fageria, 1998).

De acordo com Primavesi et al. (2006a), esse índice é de fácil estimativa e de baixo custo, pois utiliza apenas o teor de $\mathrm{N}$ total da planta e a massa seca da forragem de parcelas adubadas e não adubadas. Em pastagens manejadas intensivamente, onde se usam doses elevadas de $\mathrm{N}$, conhecer a recuperação do $\mathrm{N}$ do fertilizante pelas plantas torna-se importante para maximizar a eficiência do seu uso e minimizar o impacto ambiental.

A RNA foi influenciada pelas doses e anos de recuperação da pastagem (Figura 2B), apresentando redução linear com o aumento das doses de $\mathrm{N}$ para o ano de 2004 e quadrática decrescente para os anos 2005 e 2006. 
(A)

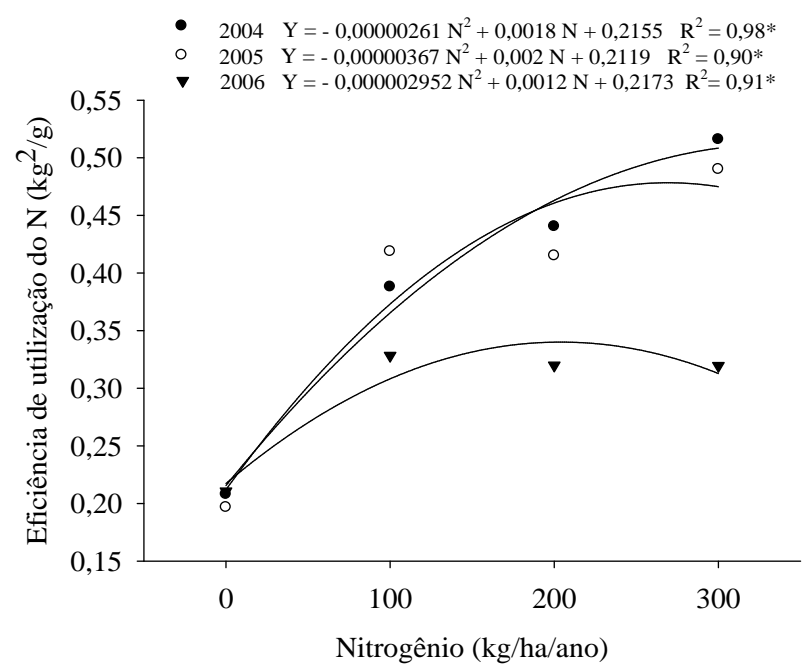

(B)

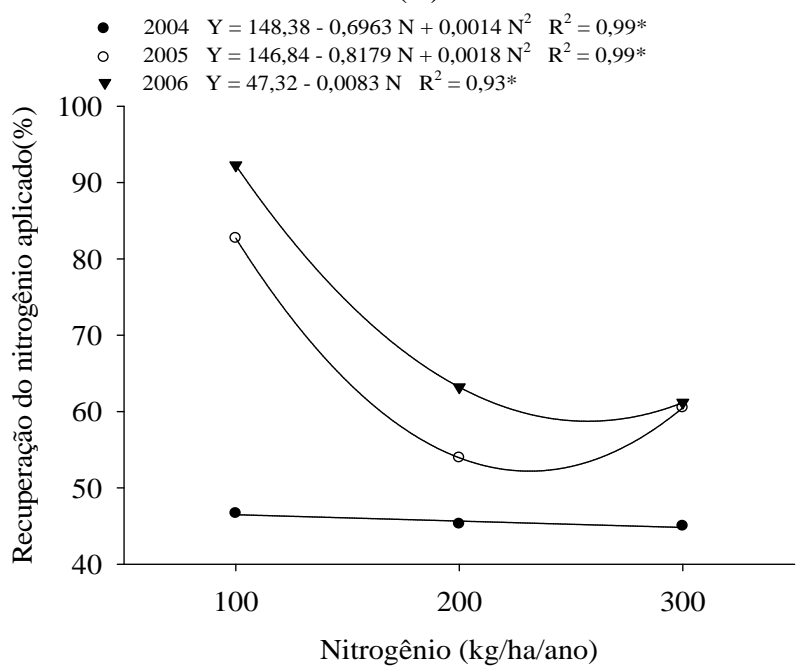

Figura 2 - Eficiência de utilização do N (A) e recuperação do N aplicado (B), em função de doses e anos de recuperação da pastagens do capim-marandu (média de três cortes por ano). *Nível de significância de 5\% (P<0.05).

Na dose de $100 \mathrm{~kg} / \mathrm{ha} / \mathrm{ano}$, a RNA observada foi superior em 4,0; 27 e 34,0\%, quando comparada com a dose máxima para os anos de 2004, 2005 e 2006, respectivamente. No ano de 2006, na dose de $100 \mathrm{~kg} / \mathrm{ha} /$ ano, a RNA mostrou-se maior em 49 e $10 \%$ quando comparada a 2004 e 2005 . Já na dose de 300 kg/ha/ano, essa diferença foi de 26 e 1,0\% em relação a 2004 e 2005, respectivamente.

Resultados de pesquisa têm mostrado que taxa de recuperação do $\mathrm{N}$ aplicado como fertilizante diminui à medida que se aumenta a dose aplicada no solo (Primavesi et al., 2006a; Cantarella, 2007).

O menor valor de RNA foi de $45 \%$ e ocorreu no ano de 2004 , na dose de $300 \mathrm{~kg} / \mathrm{ha} / \mathrm{ano}$; já o maior valor foi de $92 \%$ e ocorreu em 2006 na dose de 100 kg/ha/ano. Whitehead (1995) verificou que a recuperação do fertilizante aplicado em pastagens variou dentro dos limites de 50 a $80 \%$ e, com maior freqüência, entre 65 e $70 \%$.

Corsi (1994) explica que a recuperação do nitrogênio aplicado pode ser maior que $80 \%$ em gramíneas tropicais desde que o fertilizante seja adequadamente aplicado. Os valores de RNA podem atingir valores elevados, podendo passar de $100 \%$, e isso ocorre devido, no cálculo da RNA, à não consideração das diferenças de $\mathrm{N}$ existente no solo e o do fertilizante aplicado (Martha Júnior et al., 2009).

Esse menor aproveitamento do $\mathrm{N}$ aplicado (RNA), com o aumento das doses, já era esperado, devido a maior produção de massa seca (Costa et al., 2010) concentração de nutriente (Costa et al., 2009a) e extração de N pelas plantas (Costa et al., 2009b), nas maiores doses aplicadas. Diante disso, nessas maiores doses há uma maior chance de perdas do nutriente por volatilização, lixiviação, desnitrificação e lavagem superficial.

Outros aspectos do presente trabalho, que possivelmente contribuíram para a redução dos valores de aproveitamento do $\mathrm{N}$ aplicado (RNA), podem ser citados: a última coleta das plantas foi realizada um mês após o último parcelamento podendo ainda, após esse período, a forrageira absorver o $\mathrm{N}$ aplicado; foram coletados e analisados, em cada corte, apenas as folhas e caules acima de $20 \mathrm{~cm}$, portanto, não foi avaliado o $\mathrm{N}$ acumulado nas raízes e parte aérea não coletada.

No ano de 2004, observou-se menor aproveitamento do $\mathrm{N}$ em todas as doses aplicadas (Figura 2B). Certamente, em 2004, primeiro ano do estudo, as plantas do capimmarandu, que se encontravam em estágio moderado de degradação apresentavam, também, um sistema radicular menos desenvolvido e, com isso, menor capacidade de absorção. Nos anos seguintes (2005 e 2006), devido à grande resposta da forrageira à adubação nitrogenada (Costa et al., 2010), o potencial de aproveitamento foi aumentado, principalmente na dose de $100 \mathrm{~kg} / \mathrm{ha}$, com menores chances de perdas do $\mathrm{N}$ aplicado.

Segundo Hart et al. (1986), o nitrogênio do fertilizante estimula a atividade biológica do solo e o maior crescimento das raízes das plantas adubadas, fazendo com que o $\mathrm{N}$ de um maior volume de solo seja absorvido por essas plantas. 
Na avaliação da RNA, é importante salientar que além das perdas do $\mathrm{N}$ aplicado pelos processos já mencionados, as plantas estão, na realidade, em competição com a população microbiana do solo, sendo que o $\mathrm{N}$ aplicado no solo está, também, sujeito a uma série de transformações mediadas por microrganismos, que irão determinar as relações de equilíbrio entre as formas orgânicas e inorgânicas, sendo as formas iônicas de $\mathrm{NO}_{3}{ }^{-} \mathrm{e} \mathrm{NH}_{4}^{+}$as absorvidas pelas plantas (Moreira \& Siqueira, 2006).

Apesar de não ter sido verificado efeito significativo de doses e fontes de $\mathrm{N}$, resultados de pesquisa mostram que existe diferença na RNA entre as fontes de N utilizadas. Primavesi et al. (2006b), trabalhando com doses de $\mathrm{N}$ nas fontes de nitrato de amônio e uréia no capim-marandu, verificaram que a recuperação do $\mathrm{N}$ aplicado variou com as fontes e doses de $\mathrm{N}$, mostrando que com o aumento das doses de $\mathrm{N}$ ocorreu decréscimo na recuperação para ambas as fontes, sendo maior para a fonte de nitrato de amônio.

Existe um consenso entre os autores de que sais amoniacais, como o sulfato de amônio, apresentam menores perdas de $\mathrm{N}-\mathrm{NH}_{3}$ por volatilização que a uréia (Primavesi et al., 2001; Martha Junior et al., 2004). Enquanto os sais amoniacais apresentam perdas por volatilização entre 5 e $10 \%$ do $\mathrm{N}$ aplicado, a uréia perde, normalmente, em torno de 10 a $25 \%$, podendo atingir, em condições favoráveis, até $80 \%$.

A Eficiência Agronômica (EA) refere-se à produção adicional de massa seca pela forrageira nas parcelas adubadas em relação à não adubada por unidade de nitrogênio aplicado pelas fontes utilizadas (Fageria, 1998).

A EA não foi influenciada pelas doses e fontes de $\mathrm{N}$. Entretanto, houve significância para as doses e anos de recuperação do capim-marandu. Observa-se na Figura 3A, reduções quadráticas decrescentes dos valores de EA, com o incremento das doses de $\mathrm{N}$ aplicadas para todos os anos avaliados.

O maior valor de EA foi observado no ano de 2005 na dose de $100 \mathrm{~kg} / \mathrm{ha} / \mathrm{ano}$, com uma produção adicional de $44 \mathrm{~kg}$ de MS/kg de N aplicado. Já o menor ocorreu no ano de 2006 na dose de $300 \mathrm{~kg} / \mathrm{ha} / \mathrm{ano}$, com uma produção adicional de apenas $20,41 \mathrm{~kg}$ de $\mathrm{MS} / \mathrm{kg}$ de $\mathrm{N}$ aplicado, apresentando uma diferença de $54 \%$ quando comparados.

$\mathrm{Na}$ dose de $100 \mathrm{~kg} / \mathrm{ha} / \mathrm{ano}$, a EA foi superior em 8, 207 e 147\% em relação à dose máxima aplicada para os anos de 2004, 2005 e 2006, respectivamente. No ano de 2005 , na dose de $100 \mathrm{~kg} / \mathrm{ha} / \mathrm{ano}$, a EA foi superior em 52 e $14 \%$ em comparação com os anos de 2004 e 2006, devido à melhor distribuição de chuvas, como explicado anteriormente, favorecendo a solubilização dos fertilizantes nitrogenados no solo, contribuindo para o aumento da eficiência agronômica e resultando em maior produção de massa seca (Costa et al., 2010).

Embora a produção de massa seca da parte aérea (Costa et al., 2010) e a de lâminas foliares e colmos mais bainhas (Silva, 2007) tenham mostrado aumentos lineares com as doses de $\mathrm{N}$ aplicadas, a Figura 2A mostra, para todos os anos estudados, uma relação quadrática crescente para a eficiência de utilização do N (EU) pela forrageira; ou seja, aumentos decrescentes de EU com o aumento das doses aplicadas. Esse fato mostra que, nas maiores doses de $\mathrm{N}$, a resposta da planta em produção de massa seca, em relação à concentração de $\mathrm{N}$ nos tecidos, (EU) atingiu seu ponto máximo nas maiores doses aplicadas em todos os anos estudados (Figura 2A), justificando-se, assim, uma redução na Eficiência Agronômica (produção adicional de massa seca nas parcelas adubadas em relação às não adubadas por unidade de $\mathrm{N}$ aplicado) (Figura 3A). Primavesi et al. (2004) relataram que, de maneira geral, a resposta máxima de gramíneas forrageiras à adubação nitrogenada está na faixa de 300 a $400 \mathrm{~kg} / \mathrm{ha} / \mathrm{ano}$. Portanto, na maior dose estuda no presente trabalho $(300 \mathrm{~kg} / \mathrm{ha} /$ ano), possivelmente, esse limite de resposta tenha sido atingido (Figura 3A).

Em estudo da eficiência agrônomica do capimmarandu, Primavesi et al. (2006a), verificaram que os melhores índices ocorreram quando se aplicaram as menores doses de $\mathrm{N}$, ocorrendo redução nos valores desses índices com o aumento das doses de $\mathrm{N}$.

A Eficiência Fisiológica (EF) ou Eficiência Biológica representa a produção adicional de massa seca pela forrageira nas parcelas adubadas em relação à não adubada, por unidade de $\mathrm{N}$ adicional acumulado nas plantas dessas parcelas (Fageria, 1998).

A EF não foi influenciada pelas doses e fontes de N. Observou-se significância apenas para as doses e anos de recuperação da pastagem. Para todos os anos de recuperação do capim-marandu, houve redução linear da EF com o incremento nas doses de $\mathrm{N}$ aplicadas (Figura 3B). Portanto, os maiores valores de EF foram observados nas doses de $100 \mathrm{~kg} / \mathrm{ha} / \mathrm{ano}$ e os menores ocorreram na dose máxima em todos os anos avaliados. Os valores de EF variaram na amplitude de $29,49 \mathrm{~kg}$ de $\mathrm{MS} / \mathrm{kg}$ de $\mathrm{N}$ acumulado (na dose máxima no ano de 2006) até 66,02 kg de $\mathrm{MS} / \mathrm{kg}$ de $\mathrm{N}$ acumulado (na dose de $100 \mathrm{~kg} / \mathrm{ha} / \mathrm{ano}$ no ano de 2004), apresentando uma diferença de 56\%, quando comparados. 
(A)

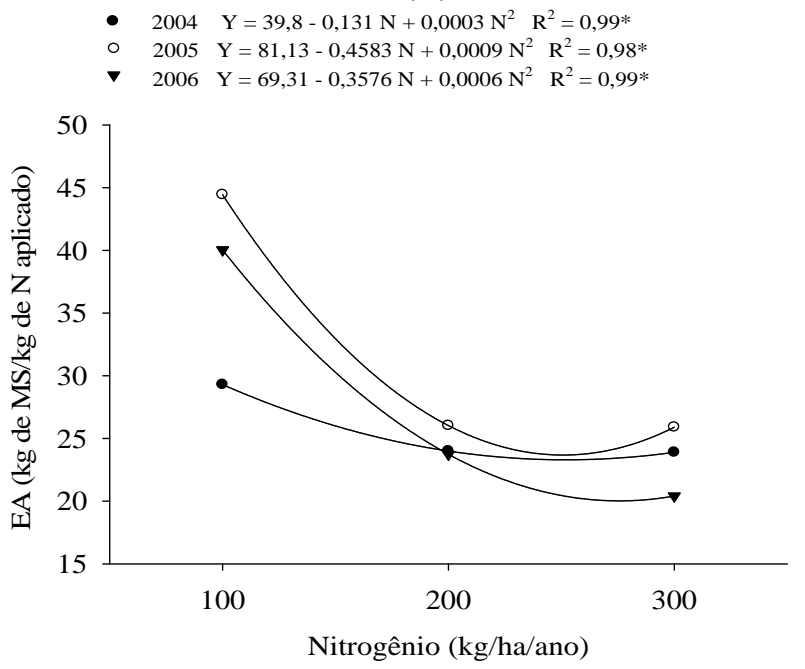

(B)

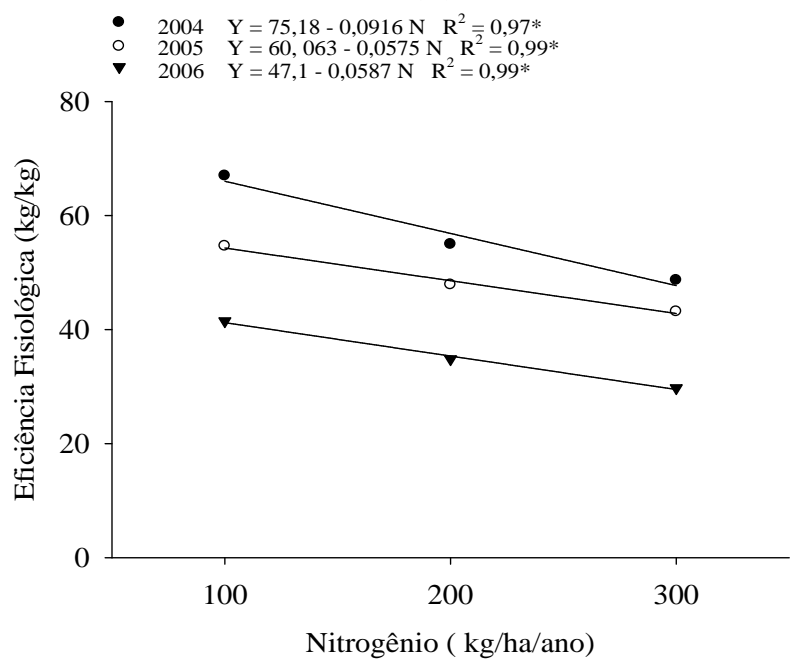

Figura 3 - Eficiência agronômica (A) e Eficiência fisiológica (B) em função de doses e anos de recuperação do capimmarandu (média de três cortes por ano). *Nível de significância de $5 \%(\mathrm{P}<0.05)$.

$\mathrm{Na}$ dose de $300 \mathrm{~kg} / \mathrm{ha} / \mathrm{ano}$ ocorreu uma diminuição de 27,21 e $28 \%$, em relação à dose de 100 kg/ ha/ano, para os anos de 2004, 2005 e 2006, respectivamente. Os maiores valores de EF nas menores doses de $\mathrm{N}$ foram observados no ano de 2004, mostrando aumento de 18 e $38 \%$ em relação aos anos de 2005 e 2006, respectivamente.

Interessante destacar que, comparando-se as Figuras 3B (EF) e 2B (RNA), observa-se que, com relação aos anos de recuperação da forrageira estudados, houve uma inversão: no ano de 2004 houve a menor RNA, e no de 2006 a maior (Figura 2B), para a EF ocorreu o contrário (Figura 3B).

Em ambos os casos, no ano de 2005, observou-se comportamento intermediário. Disso se deduz que, no ano de 2004, a forrageira recuperou menor quantidade do $\mathrm{N}$ aplicado (Figura 2B), mas foi mais eficiente em produzir massa seca por unidade de $\mathrm{N}$ absorvido do adubo aplicado (Figura 3B). A Figura 2A, referente à eficiência de utilização do N aplicado (Siddiqi \& Glass, 1981), mostra que, embora não tenham sido observadas diferenças entre os anos 2004 e 2005, o ano de 2006 foi, em todas as doses de N aplicadas, aquele que apresentou menor EU, confirmando, portanto, a afirmativa anterior.

\section{CONCLUSÕES}

A eficiência de utilização de $\mathrm{N}$ pelo capimmarandu aumentou enquanto que a recuperação do $\mathrm{N}$ aplicado, a eficiência agronômica e a eficiência fisiológica diminuíram com o aumento das doses de $\mathrm{N}$ aplicadas. Em todos os casos, os índices foram influenciados pelos anos de recuperação da forrageira estudadas, mas não pelas fontes de nitrogênio utilizadas.

\section{REFERÊNCIAS BIBLIOGRÁFICAS}

CANTARELLA, H. Nitrogênio. In: NOVAIS, R.F.; ALVARES, V.H.; BARROS, N.F.; FONTES, R.L.F.; CANTARUTTI, R.B.; NEVES, J.C.L. (Orgs.). Fertilidade do solo. Viçosa, MG: Sociedade Brasileira de Ciência do Solo, 2007. v.1, p.375-470.

CORSI, M. Adubação nitrogenada das pastagens. In: SIMPÓSIO PASTAGENS, FUNDAMENTOS DA EXPLORAÇÃO RACIONAL, 2., 1994, Piracicaba. Anais... Piracicaba: FEALQ, 1994. p.121-153.

COSTA, K.A.P.; FAQUIN, V.; OLIVEIRA, I.P. Doses e fontes de nitrogênio na recuperação de pastagens do capim-marandu. Arquivo Brasileiro de Medicina Veterinária e Zootecnia, Belo Horizonte, v.62, n.1, p.192199, 2010.

COSTA, K.A.P.; FAQUIN, V.; OLIVEIRA, I.P.; SEVERIANO, E.C.; OLIVEIRA, M.A. Doses e fontes de nitrogênio na nutrição mineral do capim-marandu.

Ciência Animal Brasileira, Goiânia, v.10, n.1, p.115-123, 2009a. 
COSTA, K.A.P.; FAQUIN, V.; OLIVEIRA, I.P.; SEVERIANO, E.C.; SIMON, G.A.; CARRIJO, M.S. Extração de nutrientes do capim-marandu sob doses e fontes de nitrogênio. Revista Brasileira de Saúde e Produção Aninal, Goiânia, v.10, n.4, p.801-812, 2009 b.

\section{EMPRESA BRASILEIRA DE PESQUISA}

AGROPECUÁRIA. Centro Nacional de Pesquisa de Solos. Ministério da Agricultura e do Abastecimento. Manual de métodos de análise de solo. 2.ed. rev. e atual. Rio de Janeiro, 1997. 212p.

\section{EMPRESA BRASILEIRA DE PESQUISA}

AGROPECUÁRIA. Centro Nacional de Pesquisa de Solos. Ministério da Agricultura e do Abastecimento. 2.ed. Sistema brasileiro de classificação de solos. Rio de Janeiro, 2006. 306p.

ESPINDULA, M.C.; ROCHA, V.S.; SOUZA, M.A.de; GROSSI, J.A.S.; SOUZA, L.T.de. Doses e formas de aplicação de nitrogênio no desenvolvimento e produção da cultura do trigo. Ciência e Agrotecnologia, v.34, n.6, p.1404-1411, Nov./dez., 2010.

FAGERIA, N.K. Otimização da eficiência nutricional na produção das culturas. Revista Brasileira de Engenharia Agrícola Ambiental, Campina Grande, v.2, p.6-16, 1998.

FERREIRA, D.F. Análises estatísticas por meio do Sisvar para Windows versão 4.0. In: Reunião Anual da Região Brasileira da Sociedade internacional de Biometria. UFSCar, São Carlos-SP, p.255-258, 2000.

HART, P.B.S.; RAYNER, J.H.; JENKINSON, D.S. Influence of pool substittution on the interpretation of fertilizers experiments with ${ }^{15} \mathrm{~N}$. Journal of Soil Science, Oxford, v.37, p.389-403, 1986.

MALAVOLTA, E.; VITTI, G.C.; OLIVEIRA, S.A. Avaliação do estado nutricional das plantas: princípios e aplicações. 2.ed. Piracicaba: Potafos, 1997. 319p.

MARTHA JÚNIOR, G.B.; CORSI, M.; TRIVELIN, P.C.O.; ALVES, M. C. Nitrogen recovery and loss in a fertilized elephant grass pasture. Grass and Forage Science, Reading, v.59, n.1, p.80-90, 2004.

MARTHA JÚNIOR, G.B.; CORSI, M.; TRIVELIN, P.C.O.; VILELA, L. Recuperação de $15 \mathrm{~N}$-ureia no sistema solo- planta de pastagem de capim-tanzânia. Revista Brasileira de Ciência do Solo, Viçosa, v.33, n.1, p.95-101, 2009.

MARTHA JUNIOR, G.B.; VILELA, L.; SOUSA, D.M.G. Adubação nitrogenada. In: Cerrado: uso eficiente de corretivos e fertilizantes em pastagens. Planaltina: Embrapa Cerrados, 2007. p.117-144.

MOREIRA, F.M.S.; SIQUEIRA, J.O. Microbiologia e bioquímica do solo. 2.ed. atual. e ampl. Lavras: UFLA, 2006. 729p.

PEGORARO, R.F.; MISTURA, C.; WENDLING, B.; FONSECA, D.M.da; FAGUNDES, J.L. Manejo da água e do nitrogênio em cultivo de capim-elefante. Ciência e Agrotecnologia, v.33, n.2, p.461-467, mar./abr., 2009.

PRIMAVESI, O.; CORRÊA, L.A.; PRIMAVESI, A.C. Adubação com uréia em pastagem de Cynodon dactylon cv. Coastcross sob manejo rotacionado: eficiência e perdas. São Carlos: Embrapa Pecuária Sudeste, 2001. 42p. (Circular técnica, 30).

PRIMAVESI, O.; PRIMAVESI, A.C.; CORREA, L.A.; SILVA, A.G.; CANTARELLA, H. Lixiviação de nitrato em pastagens de coastcross adubada com nitrogênio. Revista Brasileira de Zootecnia, Viçosa, v.35, n.3, p.683-690, 2006a.

PRIMAVESI, A.C.; PRIMAVESI, O.; CORRÊA, L.A.; SILVA, A.G.; CANTARELLA, H. Nutrientes na fitomassa de capim-marandu em função de fontes e doses de nitrogênio. Ciência e Agrotecnologia, Lavras, v.30, n.3, p.562-568, $2006 b$.

SHAVIV, A. Improvement of fertilizer efficiency: product processing, positioning and application methods.

Proceedings International Fertility Society, v.469, p.123, 2001.

SIDDIQI, M.Y.; GLASS, A.D.M. Utilization index: a modified approach to the estimation and comparison of nutrient utilization efficiency in plants. Journal of Plant Nutrition, v.4, n.3, p.289-302, 1981.

SILVA, D.R.G. Características nutricionais e eficiência da adubação nitrogenada do capim-marandu de pastagens em estado moderado de degradação sob doses e fontes de nitrogênio. 2007. 58p. (Dissertação de Mestrado em Ciência do Solo)-Universidade Federal de Lavras, Lavras, 2007. 
SOUSA, D.M.G.; LOBATO, E. Cerrado: correção do solo e adubação. 2.ed. Brasília: Embrapa Informação Tecnológica, 2004. 416p.
WHITEHEAD, D.C. Volatilization of ammonia. In: . Grassland nitrogen. Wallingford: $\mathrm{CAB}$ International, 1995. p.152-179. 